\title{
Emulsion macromonomer cross-linking. A preparative method for oxidation-responsive nanoparticles with a controlled network structure
}

Giona Kilcher, Craig Duckham, Nicola Tirelli

\section{Supplementary material}

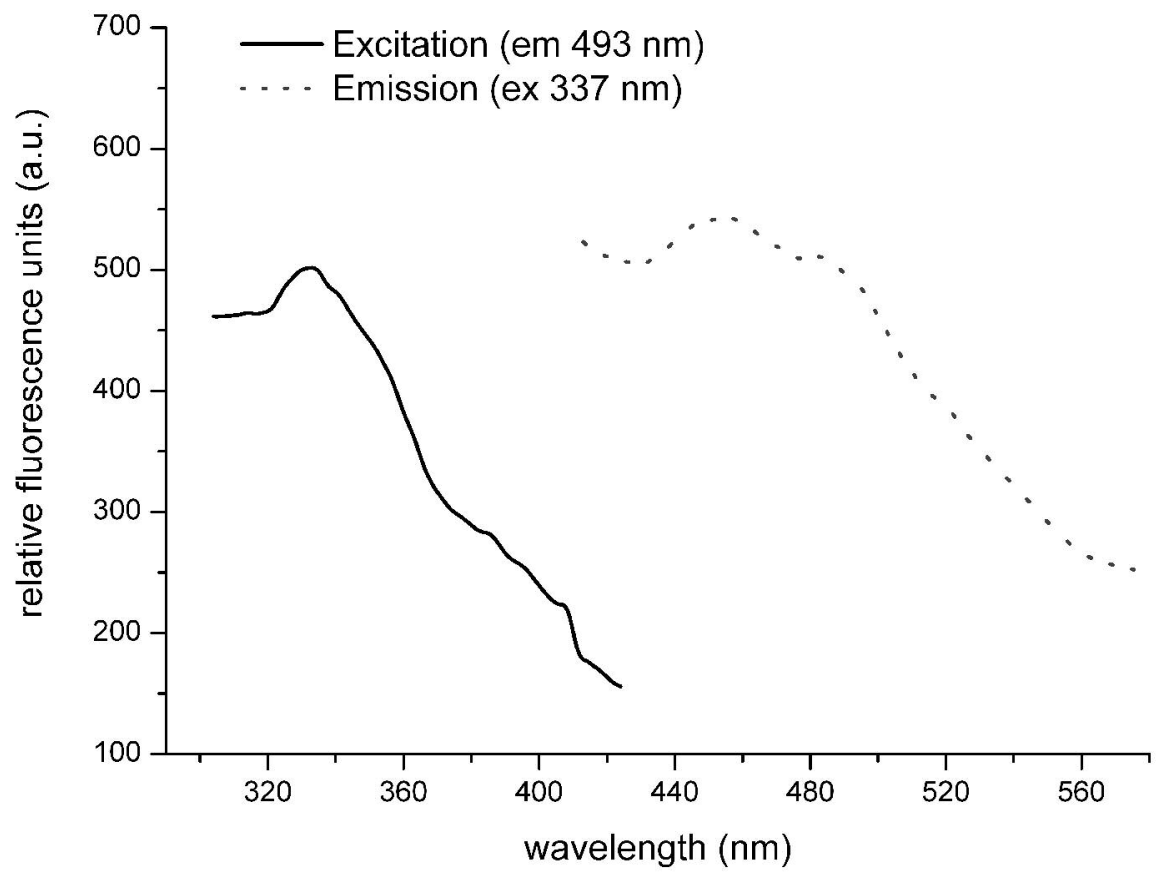

Figure 1. Excitation and emission spectra of $P 2$ nanoparticles $(1 \mathrm{mg} / \mathrm{ml}$ in distilled water after dialysis) featuring a 0.5 mole $\%$ of dansyl-terminated polysulfide chains. In terms of the precise localisation of the emission peaks, the fluorescence spectra are strongly affected by the nanoparticles scattering, which, however, does not hinder their detection through optical microscopy or even naked eye. 


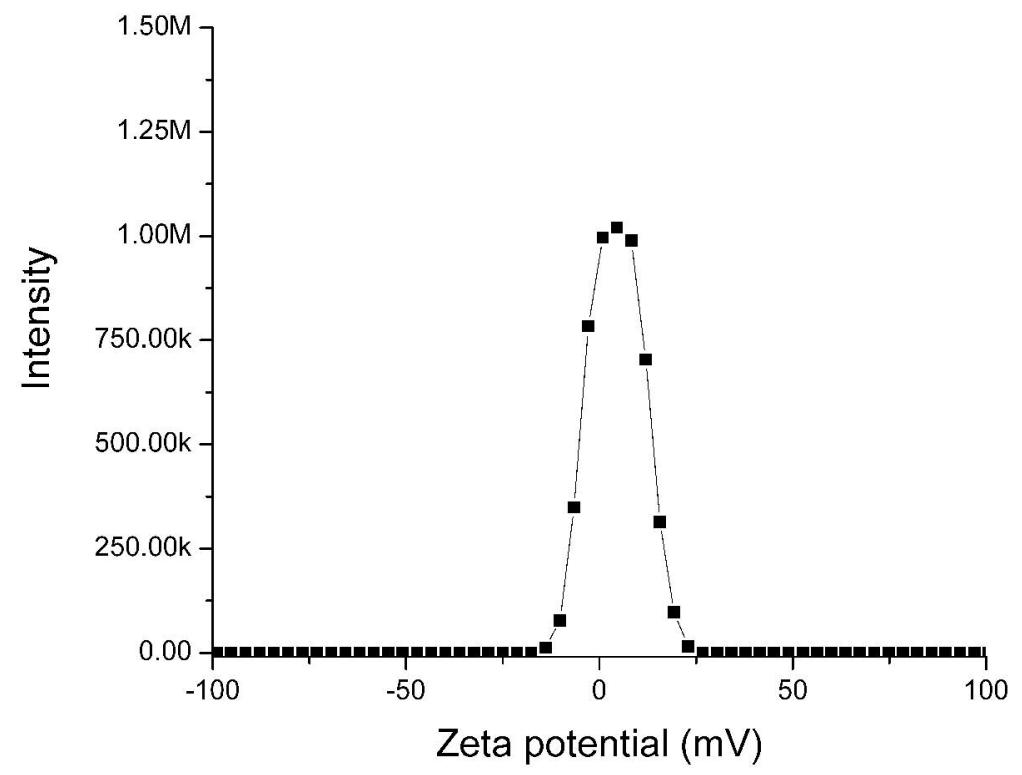

Figure 2, Zeta potential of $\mathrm{P} 2$ nanoparticles in water at $\mathrm{pH}=7.3$ 


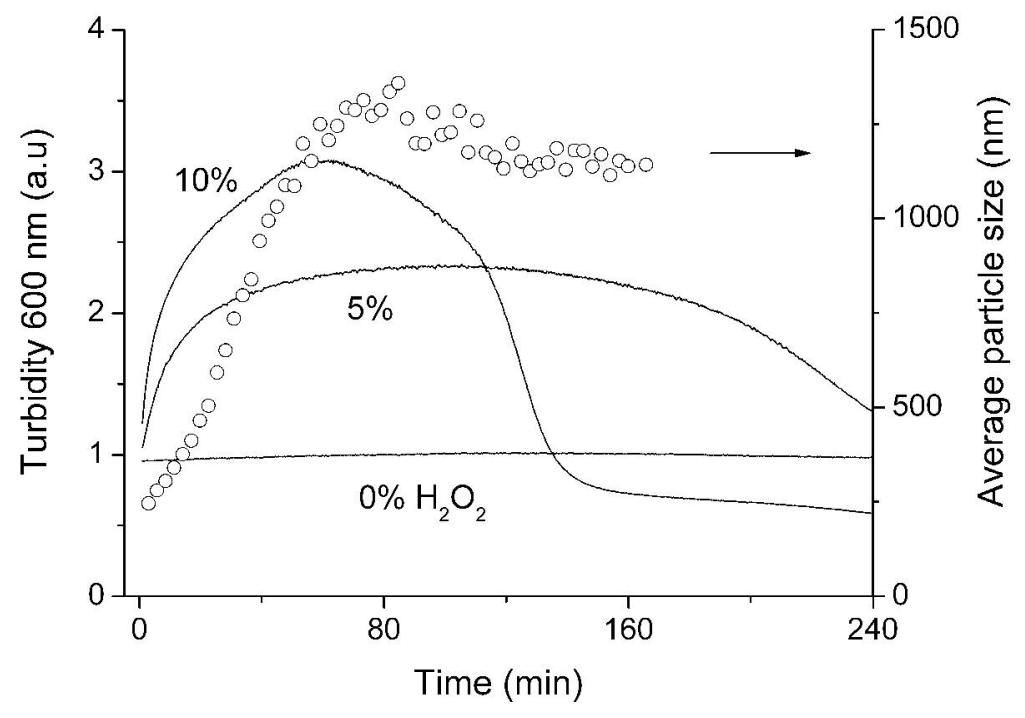

Figure 3. Evolution of turbidity (solid line) as a function of time and $\mathrm{H}_{2} \mathrm{O}_{2}$ concentration and of average particle size (open circles) as a function of time for particles $\mathrm{P} 1$ incubated in at $37^{\circ} \mathrm{C}$ and $\mathrm{pH}=7.3$. 